\title{
Fluorouracil/Leucovorin Calcium/Levamisole
}

National Cancer Institute

\section{Source}

National Cancer Institute. Fluorouracil/Leucovorin Calcium/Levamisole. NCI Thesaurus.

Code C9813.

A combination of agents containing fluorouracil, leucovorin calcium, levamisole. 